\section{TOO MANY HOOPS FOR TODAY'S PRACTITIONERS}

The rapid proliferation of regulation in dentistry has led to an unprecedented demand for advisory services, according to the British Dental Association (BDA) and Dental Protection.

Dental Protection's team of 48 dentolegal advisers has opened 3,700 new case files since the beginning of 2010 and responded to almost 10,000 helpline calls. The BDA has seen the number of calls taken by advisors each month increase by more than $40 \%$ in the last three years, leading the BDA to almost double its number of advice staff. It has also seen an increase in the complexity of advice required, with multiple contacts to help them confront specific issues.

'There is a widespread feeling that there are too many hoops for practitioners to jump through,' said Kevin Lewis, Director of Dental Protection.

HTM 01-05, PCT/LHB practice inspections, HIW registration and inspections in Wales and the fast-approaching Care Quality Commission registration are all part of today's compliance demands, and GDC revalidation is also not far away.

Lewis called for more reasonable and proportional regulation of the dental healthcare environment and commented that: 'The evidence base for many of these new requirements is sketchy or non-existent. The current environment is wasting the time, energy and money of many practitioners who are already doing an excellent job for their patients.'

'The BDA will continue to campaign for regulation not to be allowed to affect the delivery of patient care,' said Susie Sanderson, Chair of the BDA's Executive Board.

\section{CHANGES TO ANAESTHESIA LEGISLATION FOR HYGIENISTS AND THERAPISTS}

Dental hygienists and dental therapists have been added to the group of healthcare professionals who are able to prescribe local anaesthetic under a patient group direction (PGD).

A PGD is a legal framework that allows a listed group of healthcare professionals to administer medicines to a group of patients, without the need for a written patient-specific prescription or instruction from the approved prescriber.

An injection of local anaesthetic involves the use of a prescription-only medicine (POM) which means that traditionally it can only be prescribed by a doctor or a dentist. Legislation was introduced throughout the UK in 2000 to allow certain other healthcare pro- fessionals to administer POMs in specific circumstances. In 2008 it became apparent that dental hygienists and therapists had been missed off the list.

'I am delighted that this situation has now been resolved,' said dental therapist and member of the GDC's Fitness to Practise panel Keddie Kelsall. 'It allows dental hygienists and therapists to carry out their roles more effectively and will help to give patients confidence in their dental professionals.'

The legislation, which came into force on 1 June 2010, also means that dental hygienists and therapists can perform the sale, supply or oral administration of fluoride supplements and toothpastes with high fluoride content.

\section{HONORARY DOCTORATE FOR PROFESSOR SCULLY}

Professor Crispian Scully CBE has received a doctorate from the University of Helsinki, Finland in recognition of his international leadership in oral medicine and pathology, and in special care dentistry.

In particular the honorary award acknowledges his discovery of viral nucleic acids in oral cancer which, with further studies, established a viral aetiology for a range of oral neoplasms and implicated sexual transmission.

Professor Scully is Head of the Maxillofacial Medicine and Surgery Department at UCL Eastman Dental Institute and has published over 40 books and around 900 papers.

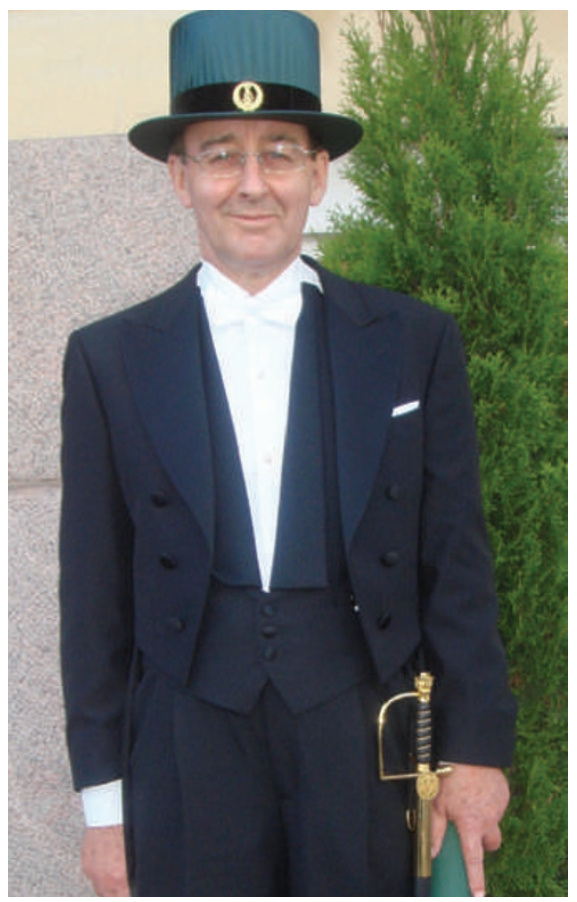

\title{
DENTISTS ADVISED TO CHECK TECHNICIANS' REGISTRATION
}

The General Dental Council (GDC) has prosecuted Mr Anthony Woodland of Bridgwater, Somerset, for unlawfully using the title 'dental technician'.

The Dental Technologists Association (DTA) advises UK dentists to check that the dental technicians that they work with are registered with the GDC.
GDC registration was introduced for dental technicians in 2007 to ensure that their work is carried out by properly trained and qualified professionals. Like other registrants, dental technicians must have professional indemnity cover, undertake continuing professional development
(CPD) and commit to uphold the GDC's standards.

The DTA has more than 1,800 members and celebrates its 21st anniversary this year. President John Stacey said: 'Dental technicians must renew their GDC registration by 31 July so 1 August 2010 would be a good date for dentists to ask for proof of registration - something they have a duty to do.' 